
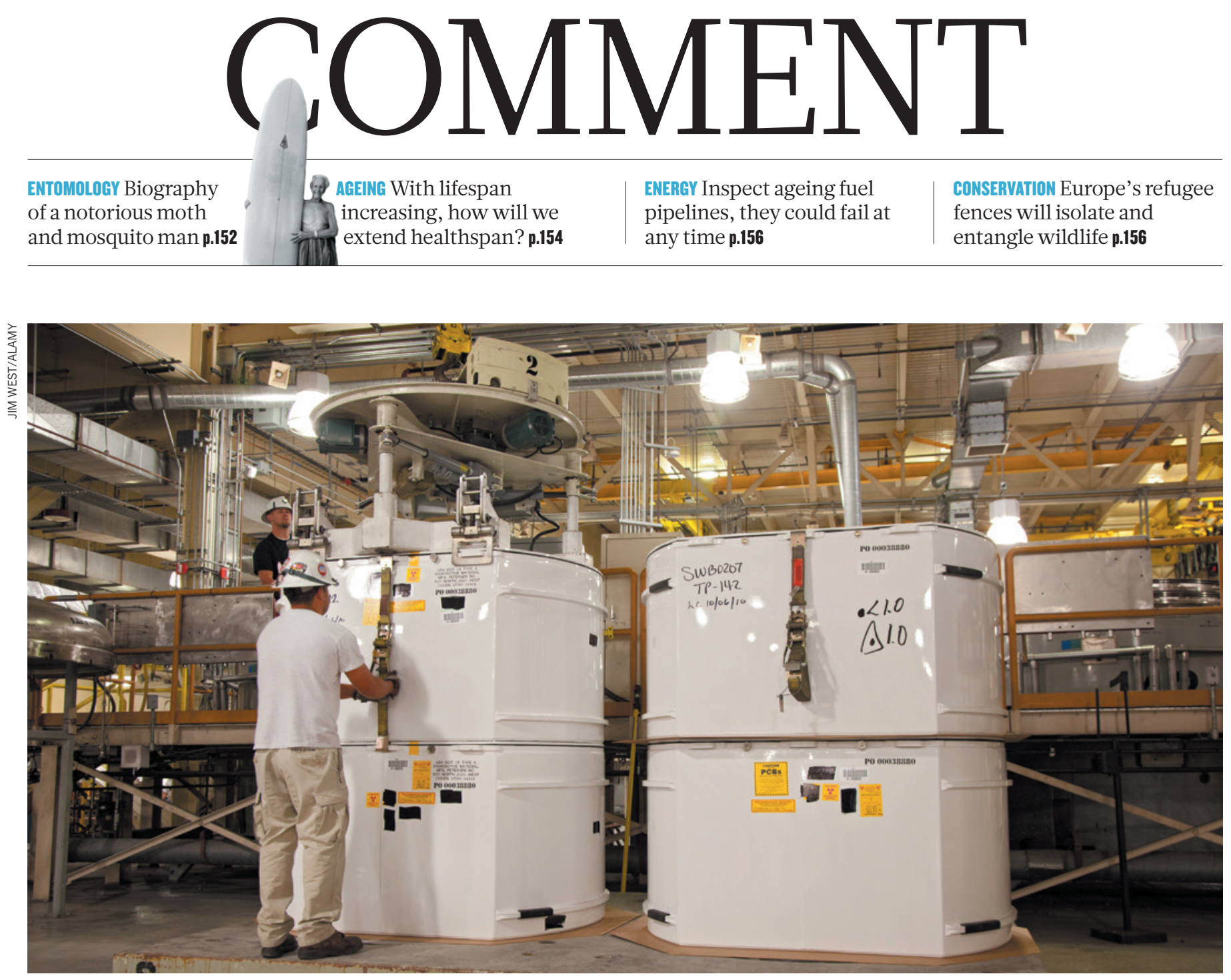

Drums containing contaminated materials from the US nuclear-defence programme are stored at the Waste Isolation Pilot Plant in New Mexico.

\title{
Reassess New Mexico's nuclear-waste repository
}

Proposals to bury plutonium from nuclear weapons must address chemical interactions and intrusion risks, say Cameron L. Tracy, Megan K. Dustin and Rodney C. Ewing.

$\mathrm{M}$ ore than 600 metres below ground near Carlsbad, New Mexico, is the world's only operating deep geological repository currently accepting transuranic nuclear waste: that contaminated by elements heavier than uranium. The Waste Isolation Pilot Plant (WIPP), run by the US Department of Energy (DOE), is used to dispose of laboratory equipment, clothing and residues from the nation's nuclear-defence programme. In the past 15 years, around 91,000 cubic metres (equivalent to covering a soccer field to a depth of about 13 metres) of such transuranic waste, mostly of relatively low radiation levels, has been placed there.

The main contaminants are long-lived isotopes of plutonium (mainly plutonium-239, with a half-life of 24,100 years, and plutonium-240, with a half-life of 6,560 years) and shorter-lived isotopes of americium and curium. In rooms carved out of a 250-million-year-old salt bed, the waste is stored in hundreds of thousands of plasticlined steel drums. The repository is now at about half of its planned capacity and is to be sealed in 2033 .
The DOE is responsible for performing safety assessments to ensure that WIPP will not exceed limits on exposure to radioactivity, as set by the US Environmental Protection Agency (EPA), for 10,000 years.

But new demands are emerging. An arms-control agreement with Russia made in 2000 obliges the United States to dispose of 34 tonnes of plutonium from dismantled nuclear weapons ${ }^{1}$. Following the terms of the agreement, the United States planned to convert the material into a fuel - mixed (uranium and plutonium) oxide, or MOX $>$ 
- to burn in commercial nuclear-power plants. But faced with soaring construction costs for a MOX fabrication facility at the Savannah River Site in South Carolina, the DOE has commissioned evaluations of alternatives ${ }^{2}$.

The most recent report ${ }^{3}$, published in August 2015, recommends burying the weapons' plutonium at WIPP. Judging the repository's performance to have been "successfully demonstrated", the DOE's Red Team expert panel proposes that the 34 tonnes of weapons plutonium can be added to WIPP once it has been diluted to low concentrations comparable to that of the transuranic waste at WIPP.

In fact, WIPP's safety record is mixed. On 14 February 2014, a burst drum released small quantities of plutonium and americium to the surface (with a radioactivity of around 100 millicuries, or 3.7 gigabecquerels $)^{4}$. Airborne radioactive material reached the surface through the ventilation system and spread 900 metres from the repository's exhaust shaft. Twenty-one workers were exposed to low levels of radioactivity, the highest dose equivalent to that from a chest $\mathrm{X}$-ray. Nine days earlier, smoke from a burning truck filled the underground workings and shaft, damaging mechanical, electrical and ventilation systems.

The DOE says that such accidents do not compromise the long-term performance of the repository. We agree that they need not - if lessons are learned. Our concern is not the events' severity but that they were unanticipated. These accidents illustrate how difficult it is to predict potential failures of such a disposal system over millennia. For example, assumptions about the repository's geochemistry or the likelihood of drilling into it can lead to underestimates of the risks.

Before expanding WIPP's plutonium inventory, the DOE must examine more carefully its safety assesment for performance that stretches to 10,000 years and beyond.

\section{CULTURE OF COMPLACENCY}

The 2014 radioactive leak at WIPP was caused by heat from a chemical reaction in a drum $^{4}$. Plutonium-contaminated nitrate salts, a waste product of plutonium purification at Los Alamos National Laboratory (LANL) in New Mexico, reacted with an organic, wheatbased commercial cat litter used as an absorbent for liquid wastes. The heat popped the lid. Although sensors detected the released radioactivity and diverted exhaust air through filters, some radioactive material leaked through. WIPP operators sealed the leak in the filtration system and sealed off the room in which the leak occurred. The breached drum remains in the repository.

Analyses of the accidents ${ }^{4}$ by the DOE have documented a lack of a 'safety culture' at WIPP. The facility's successful operation for 15 years had bred complacency. The failures

were wide-ranging: in safety assessments, control of drum contents, installation and maintenance of equipment, and preparation for an accident. An investigation of the drumpackaging procedure, for example, found "no evidence that any type of technical evaluation occurred" when selecting the organic absorbent material, even though its incompatibility with nitrate salts had been raised at LANL during waste packaging ${ }^{4}$.

From a systems-analysis perspective, the drum breach was a 'normal' accident ${ }^{5}-$ a human mistake that led to a cascade of errors and breakdowns, exacerbated by a failure to enforce safety pro-

tocols. Complex technologies are prone to unanticipated failures that can progress quickly; examples include the 1979 Three Mile Island

\section{"We cannot be certain that future inhabitants of the area will even know WIPP is there."} nuclear-plant meltdown in Pennsylvania and the 1986 Challenger space-shuttle explosion. Such accidents cannot be easily predicted, but a system designed with failure in mind can mitigate the risk.

The WIPP accident can be taken as a positive - it presents an opportunity to learn. The DOE has aggressively identified its causes and implemented corrective actions; incompatible chemicals are no longer mixed in the drums. But once the repository is closed, its contents cannot be monitored or problems fixed. We cannot be certain that future inhabitants of the area will even know that WIPP is there. To put the timescales in perspective, agriculture was developed just over 10,000 years ago.

\section{LONG-TERM SAFETY}

WIPP's present safety assessment addresses two scenarios: first, undisturbed performance and, second, human intrusion, such as inadvertently drilling through the repository in search of oil and gas ${ }^{6}$. The first foresees that after closure, the salt into which the repository is built will deform and flow around the drums to encase the waste. The model assumes that no fluids, such as brine, are present and that the site remains geologically isolated. Although the drums will be crushed, the radioactive material will be locked in the dry, solid salt, with no way to release radioactivity to the biosphere. Reliance on the geological barrier is so great that the form and composition of the waste is assumed to be unimportant; it need not even be treated.

Human intrusion could release radioactivity to the environment ${ }^{6}$. Salt deposits, layered as sediments or as salt domes, are often associated with mineral and energy resources, such as potash and hydrocarbons - oil and gas. In southeastern New Mexico, exploration for and extraction of these fuels has led to extensive drilling in the Permian
Basin, where WIPP is located.

The probability of a borehole piercing the repository in the next 10,000 years is significant. If a borehole were to puncture the repository and a brine pocket, which are known to exist in the Castile geological formation below the Salado salt formation in which the repository sits, fluid may reach the transuranic waste (see 'Accident risk'). To assess the risk of radioactive release, one must first establish the probability of borehole penetration and determine how the pressurized brine will react with the waste.

In forecasting future drilling rates, the EPA has used a 100-year historical average rate for the region, which predicts 67.3 boreholes per square kilometre over the 10,000-year regulated period ${ }^{6}$. But drilling near WIPP has risen sharply in recent years. As horizontal drilling and hydraulic-fracturing techniques have made new areas of hydrocarbon-bearing rocks accessible, the Permian Basin has become the most prolific oil-producing area in the United States. A recent 10-year historical average (2002-12) yields 148 boreholes per square kilometre over 10,000 years, more than doubling the projected risk of repository intrusion. Drilling rates, the effects of new technologies, and supply and demand pressures on hydrocarbon production are difficult if not impossible to predict centuries ahead.

The concentration of transuranic elements leached by intruding brine is also hard to estimate because of the complexity of the waste: a typical drum contains a variety of materials, such as lab coats, gloves and other laboratory equipment. Different micro-geochemical environments will develop around different waste types. Chemically organic materials, such as plastic bags, may degrade by microbial action and generate carbon dioxide. In brine, $\mathrm{CO}_{2}$ forms stable carbonate and bicarbonate complexes with plutonium and other actinides (elements 89-103), raising their concentrations in solution. Large bags of magnesium oxide powder, amounting to more than 31,000 tonnes, have been placed in WIPP disposal rooms as an 'engineered barrier. The magnesium oxide should react with the $\mathrm{CO}_{2}$ to form stable magnesium carbonates, thereby removing $\mathrm{CO}_{2}$ from solution and reducing the solubility of actinides. This presumes that the reactions proceed to completion and all the $\mathrm{CO}_{2}$ is consumed.

The safety analysis calculations for WIPP assume that there is no $\mathrm{CO}_{2}$ present, dramatically lowering actinide concentrations in the brine and thus the risk of release of radioactivity. But reliance on magnesium oxide and a series of idealized reactions to constrain the repository's geochemistry is problematic, particularly if the amount of plutonium stored at WIPP increases. As made clear by the 2014 accidents, complex interactions of materials must be carefully considered when predicting the repository's 


\section{ACCIDENT RISK}

Thousands of years in the future, inadvertently drilling a borehole through the Waste Isolation Pilot Plant, a nuclear-waste repository, and into a brine pocket could release radioactive material into the environment. The brine would interact with the waste and contaminated fluid could reach the surface through the borehole or shaft and spread within permeable rocks.

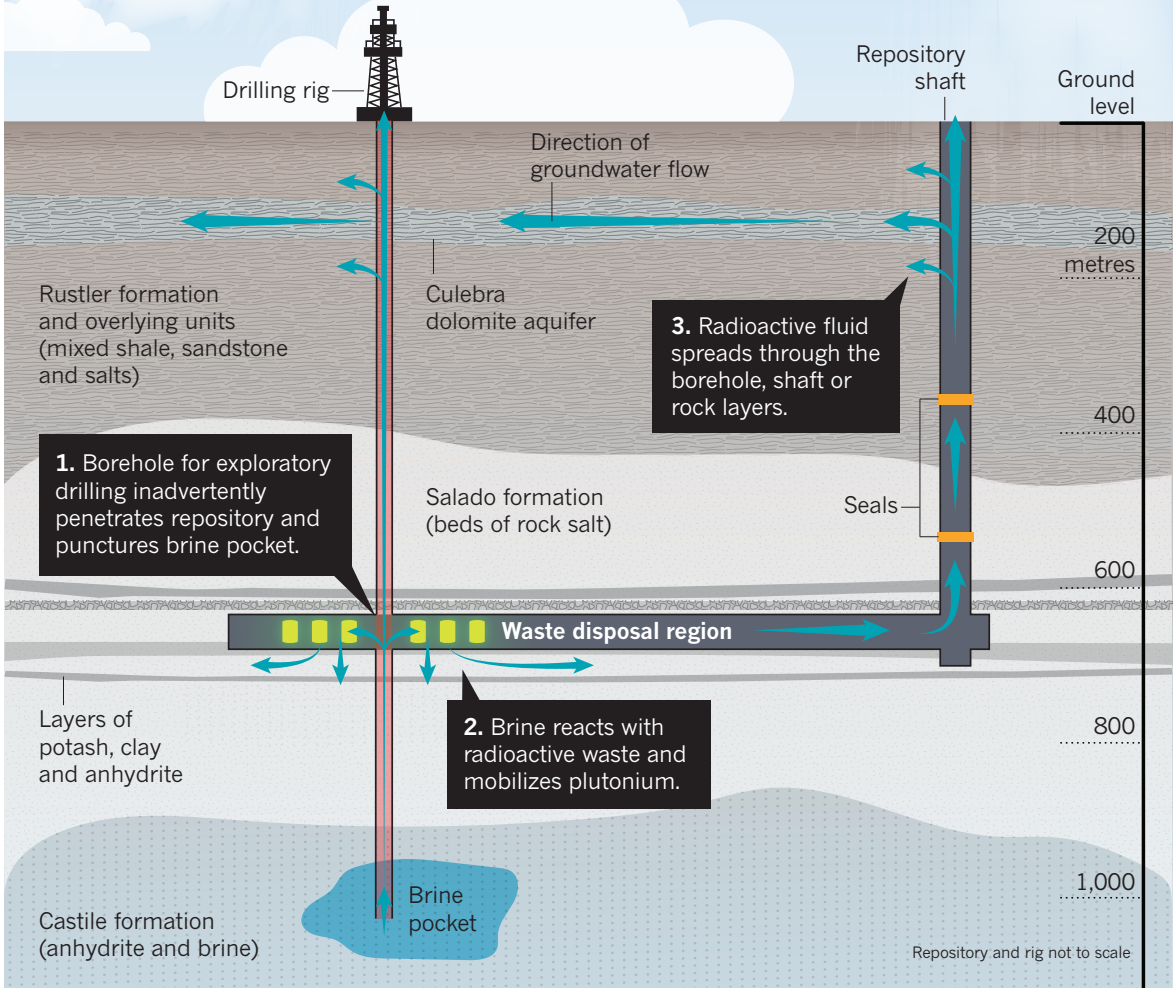

performance now and in the future.

The Red Team report proposes diluting the weapons plutonium before its disposal in an "inert adulterant" - a classified mixture of cementing, gelling, thickening and foaming agents known as stardust. The report is unclear on what is meant by 'inert'; however, inert materials are rare, particularly those that must remain so for thousands of years.

\section{PLUTONIUM DISPOSAL}

In the case of plutonium-bearing solids, demonstrating chemical inertness presents a huge challenge. In near-surface conditions, plutonium can assume a variety of oxidation states - up to four, each with different solid-state and geochemical behaviours ${ }^{7}$. Its decay product uranium-235 has two principal oxidation states, $\mathrm{U}^{4+}$ and $\mathrm{U}^{6+}$, each with different geochemical mobility ${ }^{7}$. This complexity makes it difficult to predict how the actinides will react or be transported.

Also, actinides decay mainly by the emission of a particles (energetic helium nuclei). During each decay, the daughter nucleus recoils and displaces thousands of atoms in the surrounding solid. Over time, this damage accumulates and changes the properties and chemical stability of the material. Radiation effects in actinide-bearing materials have been well documented over the past 20 years $^{8}$, but are not considered in the Red
Team's evaluation.

The 'dilute-and-dispose' proposal to convert weapons-plutonium pits to plutonium oxide for burial in WIPP ${ }^{3}$ immediately raises safety issues. The extra plutonium nearly triples the current projected plutonium (around 12 tonnes) at closure. The design and safety assessment did not envision such a large amount. WIPP's capacity would have to expand by $15 \%{ }^{1}$, increasing the likelihood that a borehole will one day intersect it.

And the changed inventory of actinides demands new assessments of interactions with the materials present, including brine and $\mathrm{CO}_{2}$. The amount of plutonium mobilized in brine depends on its solubility, which depends on its form and the amount of $\mathrm{CO}_{2}$ present after reaction with the bags of magnesium oxide.

\section{NEXT STEPS}

The current regulatory period of 10,000 years is short relative to the 24,100 -year half-life of plutonium-239, let alone that of uranium-235, which has a half-life of 700 million years. To accommodate the extra plutonium, the regulatory period might be lengthened, meaning that the probability of human intrusion during this period increases.

Some of these issues and others were raised in two 2015 reviews ${ }^{9,10}$ of the Red Team report by the consultancy High Bridge Associates of
Greensboro, Georgia. But the analysis did not consider the possibility of human intrusion.

WIPP is fulfilling an important national need - the disposal of legacy transuranic waste from US defence programmes. Its opening was the culmination of 20 years of scientific research, engineering design and public engagement. Despite the accidents, WIPP can still fulfil its mission.

However, proposals to substantially increase the plutonium inventory combined with a failure to revise the safety assessment, particularly the possibility of human intrusion, bear witness to the ease with which policy decisions can disregard the fundamental science - and risk yet another failure.

The Red Team report shows a limited effort to consider or manage inherent risks. The shortcomings of proposals to dispose of weapons plutonium at WIPP mirror the operational failings that led to the 2014 accidents. Before the DOE considers implementing these recommendations, it should look to the repository's record over the past 15 years of operation and reassess its confidence in the safe performance of the facility over the next 10,000 .

Cameron L. Tracy is a MacArthur postdoctoral fellow at the Center for International Security and Cooperation, Stanford University, California, USA.

Megan K. Dustin is a graduate fellow in the Department of Geological Sciences, Stanford University, California, USA. Rodney C. Ewing is Frank Stanton professor in nuclear security at the Center for International Security and Cooperation, Stanford University, California, USA.

e-mail:rewing1@stanford.edu

1. Clements, T., Lyman, E. \& von Hippel, F. Arms Control Today 43, 8-15 (2013).

2. US Department of Energy. Report of the Plutonium Disposition Working Group: Analysis of Surplus Weapons-Grade Plutonium Disposition Options (DOE, 2014).

3. US Department of Energy. Final Report of the Plutonium Disposition Red Team (DOE, 2015).

4. US Department of Energy. Accident Investigation Report: Phase 2, Radiological Release Event at the Waste Isolation Pilot Plant, February 14, 2014 (DOE, 2015).

5. Perrow, C. Normal Accidents: Living with High Risk Technologies (Princeton Univ. Press, 1999).

6. US Department of Energy. Compliance Recertification Application 2014 for the Waste Isolation Pilot Plant (DOE, 2014).

7. Maher, K., Bargar, J. R. \& Brown, G. E. Inorg. Chem. 52, 3510-3532 (2012)

8. Ewing, R. C. \& Weber, W. J. in The Chemistry of the Actinide and Transactinide Elements Vol. 6 3813-3888 (eds Morss, L. R., Edelstein, N. M., \& Fuger, J.) (Springer, 2010).

9. High Bridge Associates. Plutonium Disposition Study Options (High Bridge Associates, 2015).

10. High Bridge Associates. Supplemental Report, Independent Assessment of the Impact of Disposing of Surplus Weapons Plutonium at WIPP (High Bridge Associates, 2015).

The views expressed are those of the authors and not those of the US Nuclear Waste Technical Review Board, of which R.C.E. is a member. 